\title{
COBERTURA NOTICIOSA DE LA COVID-19 EN MEDIOS DE ACAPULCO: MARZO A AGOSTO 2020
}

\section{NEWS COVERAGE OF COVID-19 IN ACAPULCO MEDIA: MARCH TO AUGUST 2020}

\section{Oscar Basave Hernández}

Universidad Autónoma de Guerrero, México

(iD) https://orcid.org/0000-0001-9631-5143

\section{María Ysabel Navarrete Radilla}

Universidad Autónoma de Guerrero, México

(iD) https://orcid.org/0000-0001-5260-1922

Autor para correspondencia: Oscar Basave Hernández, email: oscarbasave@uagro.mx

\section{Resumen}

La investigación que aquí se desarrolla es de carácter descriptivo; registra la cobertura informativa en seis medios informativos con sede en Acapulco: dos impresos, El Sur y Novedades Acapulco; dos televisivos, Televisa Acapulco y Sur TV, así como dos radiofónicos, Nuestras Noticias e Informe 24, que durante seis meses, de marzo a agosto del 2020, publicaron información sobre la pandemia de la COVID-19. El objetivo de la investigación es conocer el tratamiento, las fuentes y la información que se difundió en este tiempo de los efectos sociales, económicos y la evolución del contagio del virus SARS- CoV2. La información en torno a las infecciones y sus diversas consecuencias fue de $61 \%$ y las fuentes de información que predominaron fueron las oficiales, como el gobernador de Guerrero y la presidenta municipal de Acapulco.

Palabras clave: medios de comunicación, COVID- 19, coronavirus, noticias, cobertura informativa.

\begin{abstract}
The research carried out here is descriptive in nature; registers the informative coverage in six informative media based in Acapulco: two printed, El Sur and Novedades Acapulco; two television stations, Televisa Acapulco and Sur TV, as well as two radio stations, Nuestras Noticias and Informe 24, which for six months, from March to August 2020, published information on the COVID-19 pandemic. The objective of the investigation is to know the treatment, sources and information that was disseminated at this time of the social and economic effects and the evolution of the contagion of the SARS-COV 2 virus.
\end{abstract}

Keywords: media, COVID-19, coronavirus, news, information coverage.

Global Media Journal México, 18(35), 55-70, julio - diciembre 2021. 
Recibido: 16/07/2021

Aceptado: 25/11/2021

\section{Introducción}

La aparición de la enfermedad infecciosa del coronavirus (COVID- 19, por sus siglas en inglés) que comenzó en diciembre del 2019 en China se convirtió en la primera pandemia del siglo XXI y que no sólo tuvo consecuencias para los enfermos, sino por sus formas de contagio, para la vida económica y social con el aislamiento que se extendió por un tiempo aun indefinido.

El 13 de enero se presentó el primer caso de contagio fuera de China, en Tailandia, y para el 30 ya había 7 mil 818 casos confirmados en 18 países, la mayoría de ellos en China y el 11 de marzo fue declarada pandemia (Organización Mundial de la Salud, 2020).

Como parte de las medidas de prevención en México, a mediados de marzo se anunció la cancelación de actividades y eventos masivos; a partir del 23 se inicia la Jornada Nacional de Sana Distancia y comienzan temporalmente la suspensión de actividades no esenciales y las labores como parte de la Fase 2 y el 21 de abril la Fase 3. El significado de las fases refiere a la forma de contagio, la 1 es la importación de casos, con un número reducido de infectados que contrajeron el virus fuera del país; la 2 indica el contagio del virus entre personas dentro del país y que no necesariamente tuvieron contacto con pacientes expuestos a la infección en el extranjero. La 3 es la epidemiológica, cuando el virus afecta a miles de personas en varias localidades.

A pesar de estas recomendaciones, una parte importante de la población continuó realizando sus actividades cotidianas o eventos sociales privados, que implicaba desacato a las medidas recomendadas. Las necesidades económicas, sobre todo de aquellos que no son asalariados, junto con informaciones falsas de la pandemia que se difundieron ampliamente fortalecieron la incredulidad sobre el virus.

En Acapulco, estado de Guerrero (México), no se pudo garantizar la inmovilidad social con la idea del "Quédate en casa", promovida por las autoridades federales, principalmente por tres razones: una de ellas fue el alto porcentaje de la población económicamente activa que no es asalariada y que trabaja por su cuenta en actividades informales; otra, que hubo quienes manifestaron su incredulidad ante la enfermedad y; la tercera, algunos simplemente desacataron las medidas sanitarias recomendadas a pesar de la información sobre la evolución de los contagios y decesos, así como el colapso de los hospitales para atender a los infectados, esto según la fuente que brindara la información, porque mientras afuera de las instalaciones hospitalarias se colocaban letreros que señalaban que no había espacios para la atención de enfermos, y familiares de pacientes denunciaban que no los recibían para atenderlos; y por otro lado los 
gobiernos federal y estatal aseguraban que sí había lugares.

La aparición y rápida propagación del coronavirus también dio pie a toda una serie de teorías conspirativas y de desinformación que se difundieron principalmente en las redes sociales virtuales Facebook, Twitter y WhatsApp. Que el virus era un arma biológica de fabricación china contra Estados Unidos; o de elaboración estadounidense contra los chinos; un complot para la reconfiguración de la población o su control; o de plano negar la existencia del virus. También dentro de esta campaña negra se daban las curas para aliviar la enfermedad, esto socavó la labor de las autoridades sanitarias.

El escepticismo en torno a la existencia de la COVID- 19 no sólo se expresaba en comentarios en las redes sociales, sino también en las entrevistas con los medios de comunicación masiva, cuyos reporteros preguntaban por los desacatos a las recomendaciones de evitar aglomeraciones, guardar la sana distancia y portar cubrebocas y los entrevistados manifestaban su incredulidad.

La UNESCO (2020) identificó a esa sobreabundancia de información, como "infodemia" y la catalogó como una "segunda enfermedad". Clasificaba a las noticias falsas (producidas y compartidas con motivación maliciosa), e información errónea cuando esas mentiras son difundidas sin malas intenciones, pero considera que los efectos de esas modalidades pueden ser igual de mortales a la enfermedad.

De tal manera que el periodismo se hizo necesario para la difusión de la información fidedigna brindada por las autoridades. Se considera periodismo a la actividad que es realizada por personas profesionales y acreditadas para conseguir, procesar y publicar información en medios de comunicación ya sea impresos o electrónicos, como televisión y radio, que en conjunto tienen con presencia en diversas plataformas de Internet.

Este trabajo analiza la cobertura noticiosa del coronavirus durante seis meses (de marzo a agosto del año 2020) en seis medios de comunicación con sede en Acapulco, dos de prensa, El Sur y Novedades Acapulco; dos de televisión, Televisa Acapulco y Sur $T V$; dos de radio, Informe 24 y Nuestras Noticias. Esto con el fin de responder a los planteamientos de cuáles fueron las noticias relacionadas con la COVID- 19 y qué tipo de información se difundió, así como las fuentes de información utilizadas para elaborar las notas informativas.

Si bien durante este tiempo que ha durado el confinamiento social producto de la pandemia de la COVID- 19 se ha dado una sobreabundancia de información, la UNESCO resalta la importancia de los medios de comunicación convencionales que pueden ofrecer más garantías de que la información que publican es confirmada, a diferencia de las noticias falsas que se propagaron a través de internet.

El objetivo general de esta investigación es conocer cuál es la cobertura periodística que se dio en torno al coronavirus en medios con sede en Acapulco, así como analizar la información que se publicó en torno a los efectos y evolución de la enfermedad.

Los objetivos particulares son conocer quienes fueron las fuentes de información, así como 
las actividades y acciones que se registraron en los medios, tanto las medidas de prevención y protección como las protestas que se realizaron por la suspensión de actividades no esenciales, o en reclamos de apoyos para los afectados en sus ingresos.

Se pretende responder las preguntas: ¿de qué se habló? y ¿quiénes hablaron sobre la pandemia del coronavirus en estos meses?

Esta investigación es un estudio descriptivo y, como señalan Hernández Sampieri, Fernández Collado \& Baptista Lucio (2003), busca medir y recolectar datos sobre un hecho, en este caso las notas informativas en torno a la COVID- 19.

En Guerrero existen 50 medios de comunicación masiva, los cuales tienen principalmente su sede en las ciudades más pobladas de sus respectivas regiones, como Acapulco, Chilpancingo, Iguala, Taxco, Tlapa y Altamirano. Pero es en Acapulco donde se concentra la mayoría de los medios con mayor tiraje y cobertura estatal

\section{Marco teórico}

La producción científica en torno a la cobertura de los medios de comunicación masiva sobre la COVID- 19 es incipiente. En una búsqueda realizada al respecto se encontraron apenas unos cuantos artículos con referencia del tema.

Uno de esos trabajos, es el de LázaroRodríguez \& Herrera Viedma (2020), en el cual analiza la producción de noticias en medios de comunicación digitales en España y la evolución del volumen de la información periodística. Del mismo país está el trabajo de Cantero de Julián, SidorenkoBautista \& Herranz de la Casa (2020), que también examinan el contenido de portada y su evolución conforme pasaban los días de contagio en el territorio español, así como el tratamiento de la información proporcionada por las portadas de siete periódicos.

Casero-Ripollés (2020) analiza el tema desde el consumo de noticias de la ciudadanía en el contexto de la pandemia y el impacto de la información, así como la capacidad para la detección de noticias falsas relacionadas con el coronavirus.

Por otro lado, el Observatorio Veracruzano de Medios (2020a, 2020b, 2020c) publicó tres resultados de monitoreos que refieren a ¿cuáles fueron los rasgos del discurso empleados en las noticias emitidas sobre la COVID- 19 en los portales digitales veracruzanos?, ¿quiénes hablaron y sobre qué temas en la prensa digital de Veracruz durante la COVID- 19?, y ¿cuáles fueron los actores o declarantes que aparecieron en la prensa digital veracruzana durante la contingencia sanitaria COVID- 19? Cada uno de los artículos tiene como base el monitoreo de medios informativos de Veracruz.

En este trabajo de investigación, en el que se analiza la cobertura informativa, es importante tomar en cuenta precisamente la producción de noticias, es decir, los eventos que fueron publicados en los medios de comunicación relacionados con la COVID- 19, así como el tratamiento noticioso y a sus diversas consecuencias; pero también comprender cómo es que se difunde la información en las diversas 
plataformas de internet y que no provienen de fuentes verificadas como las que se utilizan en las noticias.

En las redes sociales, lo que es la vida en línea, el control de las emociones es menor. Trejo Delarbre (2015) identifica cinco rasgos que favorecen la difusión de desinformación que son la espontaneidad, facilidad, visibilidad, permanencia y expansibilidad; aquí no se verifica lo que se comparte, sino que se hace como una mera reacción ante la información, sea real o falsa. A diferencia de los medios de comunicación convencionales que sus publicaciones pasan por varios filtros.

Alsina (2005) señala que los medios de comunicación masiva son un sistema que funciona con inputs que son los acontecimientos y produce outputs que son las noticias; estos sucesos pueden ser promovidos por fuentes de información, es decir, las oficinas o actores interesados en dar a conocer alguna información o promovido por periodistas que realizan hallazgos o por acciones no programadas. Alsina cita a Tuchman con una tipología de noticias y apunta entre otras las siguientes que tienen que ver con el objeto de esta investigación: las noticias en desarrollo y la de secuencia. Las primeras son aquellas que van produciendo acontecimientos nuevos o derivaciones que son noticias, en este caso los contagios, afectaciones a la salud y decesos, así como las consecuencias como las implicaciones por el aislamiento social. Las de secuencias, por su parte, son la serie de relatos sobre el mismo tema de acontecimientos que se van desarrollando, por ejemplo, las reacciones.

En la producción de noticias Hjarvard (2014) cita el concepto de valor noticioso y señala que es un sistema de criterios que se usan para tomar decisiones respecto a la inclusión o exclusión de noticias de un medio.

Para la provisión de noticias los medios cuentan con reporteros y con los servicios de agencias de noticias, que a su vez tienen periodistas que recopilan información; de estas partes se presentan los reportes que serán considerados para su publicación de acuerdo con los criterios de la mesa de redacción.

Hernández Ramírez (1995) apunta que los periodistas tienen cuotas de notas que garanticen la próxima edición y para ello la obtienen a través de canales formales e informales, con la asignación de fuentes informativas que suministran información constante a través de boletines, conferencias de prensa y reuniones; además en los medios se les indican órdenes de trabajo para dar seguimiento, así como la cobertura de eventos, esperados o no programados.

Las noticias que se publican en las emisiones de los medios de comunicación masiva dieron pie a la teoría de la agenda setting, que se utilizará en esta investigación como enfoque teórico. Este modelo propuesto por McCombs (2006) plantea que los temas del repertorio público son establecidos por las informaciones que dan los periodistas sobre hechos y situaciones que se brindan en forma de noticias, las cuales nos informan de los últimos acontecimientos y de los cambios en el entorno. A esta capacidad de influir en el interés público es lo que se denomina la fijación de la agenda por parte de los medios informativos. 
El público echa mano de esas pistas de relevancia que le dan los medios para organizar su propia agenda y decidir, de este modo, cuáles son los temas más importantes. Y a base de tiempo, esos temas donde las informaciones han puesto el acento se vuelven también los más importantes en la consideración pública. En consecuencia, la agenda de los medios informativos se vuelve, en gran medida la agenda pública. En otras palabras, los medios informativos establecen la agenda del público. Ese establecimiento de la relevancia entre el público, situando un tema en su repertorio de manera que se vuelva el foco de su atención y de su pensamiento $-y$, tal vez, de su acción--, constituye el nivel inicial en la formación de la opinión pública (McCombs, 2006, p. 25).

La información en torno a la COVID- 19 que se comenzó a difundir a principios de enero del 2020 fue ampliándose y expandiéndose en la medida de que los contagios se incrementaron hasta declararse pandemia global por la Organización Mundial de la Salud (2020), la enfermedad del coronavirus, así como las diversas consecuencias que tuvo la convirtió en una noticia en desarrollo y de secuencia. En el primer caso porque produjo acontecimientos nuevos o derivaciones que también fueron noticias por las reacciones sociales, tanto por el desacato a las recomendaciones sanitarias como las protestas que se generaron por la demanda de ayuda, entre otras. En desarrollo porque diariamente se producían nuevos acontecimientos propios de la enfermedad, número de contagios y de fallecimientos por esta.

El volumen de la información generada en torno al tema, al igual que la desinformación que se diseminaba con mayor rapidez que las noticias confirmadas, hizo valorar y persuadir a los receptores de datos a través del periodismo profesional que verificaran los informes a publicar.

Por ello se hace necesario el monitoreo para conocer el tratamiento que se le brinda en los reportes periodísticos a la evolución y las múltiples consecuencias de la enfermedad.

Por lo tanto, como refiere la UNESCO (2020):

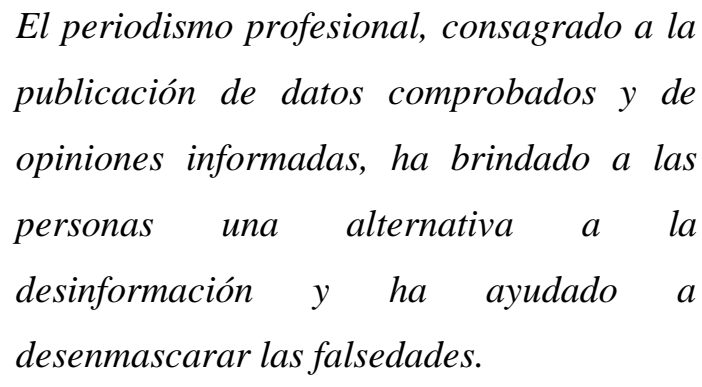

\section{Metodología}

Esta investigación es un estudio descriptivo y de análisis de contenido. Como señalan Hernández Sampieri, Fernández Collado \& Baptista Lucio (2003), los estudios descriptivos pretenden medir o recoger información sobre conceptos o variables para decir cómo es y cómo se manifiesta el fenómeno de interés; estos estudios recolectan datos que muestran un evento y el investigador debe definir sobre qué se 
van a recolectar los datos. Por el tipo de estudio no se planteó una hipótesis, debido a que se describió el comportamiento de los medios citados.

De acuerdo con Gunter (2014), el análisis cuantitativo de contenidos "se diseña con el fin de proporcionar un reporte descriptivo del contenido de un texto mediático (película, programa de televisión, anuncio, noticia periodística, sitio web, etc.)" (p. 398). Asimismo se señala que se deben "definir" las cosas que se medirán como la "unidad de análisis".

En la recolección de información y análisis de información se empleó la técnica del análisis de contenido, y las unidades de análisis fueron las notas sobre la enfermedad publicadas en los seis medios de comunicación masiva con sede en Acapulco, se decidió esto con el objetivo de describir sistemática y cuantitativamente el contenido de la comunicación, y así proporcionar un reporte en este caso, acerca de la publicación de noticias sobre el coronavirus.

Por cuanto a la muestra, Lozano (1994) señala que es necesario diferenciar entre el muestreo de fechas y el de unidades de análisis porque en el primero se definen cuántos días, ediciones o episodios son necesarios para generalizar los resultados sobre un periodo temporal determinado, luego del universo de fechas se obtienen las muestras de distintos tamaños y se comparan los resultados.

Lozano (1994), con respecto al tipo de muestreo no probabilístico de semanas compuestas, indica que se elige la semana que servirá de arranque y el día en que se desea comenzar; así, en la primera semana, se tiene un día definido por la muestra; se avanza en la segunda semana y se toma el siguiente día en el orden y lo mismo con toda las siguientes; de tal forma que se tiene una semana compuesta de un día en cada una de las semanas.

En esta investigación se consideró la semana de arranque el 23 de marzo hasta el 25 de agosto del 2020, de la cual se obtuvo un universo de 153 días. De esta cantidad de días, después de aplicar el muestreo de semana compuesta se redujo a 28 días, que se especifican en la Figura 1.

Para el registro de las unidades de análisis que son las notas periodísticas se utilizó los códigos que se indican en la Tabla 1. 


\section{Figura 1}

Muestreo de días seleccionados de acuerdo con las semanas compuestas para analizar la información.

\begin{tabular}{|cccccccc}
\hline \multicolumn{7}{|c}{ marzo '20 } \\
\hline Lu & Ma & Mi & Ju & Vi & Sá & Do \\
& & & & & & 1 \\
2 & 3 & 4 & 5 & 6 & 7 & 8 \\
9 & 10 & 11 & 12 & 13 & 14 & 15 \\
16 & 17 & 18 & 19 & 20 & 21 & 22 \\
\hline 23 & 24 & 25 & 26 & 27 & 28 & 29 \\
\hline 30 & 31 & & & & & \\
& & & & & & \\
& & junio & 20 & & \\
\hline Lu & Ma & Mi & Ju & Vi & Sá & Do \\
\hline 1 & 2 & 3 & 4 & 5 & 6 & 7 \\
\hline 8 & 9 & 10 & 11 & 12 & 13 & 14 \\
\hline 15 & 16 & 17 & 18 & 19 & 20 & 21 \\
22 & 23 & 24 & 25 & 26 & 27 & 28 \\
29 & 30 & & & & &
\end{tabular}

\begin{tabular}{|cccccccc}
\hline \multicolumn{7}{c|}{ abril '20 } \\
\hline Lu & Ma & Mi & Ju & Vi & Sá & Do \\
& & 1 & 2 & 3 & 4 & 5 \\
6 & 7 & 8 & 9 & 10 & 11 & 12 \\
13 & 14 & 15 & 16 & 17 & 18 & 19 \\
20 & 21 & 22 & 23 & 24 & 25 & 26 \\
27 & 28 & 29 & 30 & & & \\
& & & & & & \\
& & & & & & \\
\hline & & julio & 20 & & \\
\hline Lu & Ma & Mi & Ju & Vi & Sá & Do \\
& & 1 & 2 & 3 & 4 & 5 \\
\hline 6 & 7 & 8 & 9 & 10 & 11 & 12 \\
\hline 13 & 14 & 15 & 16 & 17 & 18 & 19 \\
\hline 20 & 21 & 22 & 23 & 24 & 25 & 26 \\
\hline 27 & 28 & 29 & 30 & 31 & &
\end{tabular}

\begin{tabular}{|c|c|c|c|c|c|c|}
\hline \multicolumn{7}{|c|}{ mayo '20 } \\
\hline \multirow[t]{2}{*}{ Lu } & \multirow[t]{2}{*}{ Ma } & \multirow[t]{2}{*}{ Mi } & \multirow[t]{2}{*}{ Ju } & \multirow[t]{2}{*}{ Vi } & \multirow{2}{*}{$\begin{array}{l}\text { Sá } \\
2\end{array}$} & \multirow{2}{*}{$\begin{array}{c}\text { Do } \\
3\end{array}$} \\
\hline & & & & & & \\
\hline 4 & 5 & 6 & 7 & 8 & 9 & 10 \\
\hline 11 & 12 & 13 & 14 & 15 & 16 & 17 \\
\hline 18 & 19 & 20 & 21 & 22 & 23 & 24 \\
\hline 25 & 26 & 27 & 28 & 29 & 30 & 31 \\
\hline & & agc & sto & '20 & & \\
\hline Lu & Ma & Mi & Ju & Vi & Sá & Do \\
\hline & & & & & 1 & 2 \\
\hline 3 & 4 & 5 & 6 & 7 & 8 & 9 \\
\hline 10 & 11 & 12 & 13 & 14 & 15 & 16 \\
\hline 17 & 18 & 19 & 20 & 21 & 22 & 23 \\
\hline 24 & 25 & 26 & 27 & 28 & 29 & 30 \\
\hline 31 & & & & & & \\
\hline
\end{tabular}

Tabla 1

Libro de códigos que se utilizó para recopilar la información

\begin{tabular}{ll}
\hline Fecha & Fecha en que se dio a conocer la información \\
Medio & Nombre del medio que publicó la información \\
Tipo de medio & Qué tipo de medio publicó la información, prensa, televisión o radio \\
Tema & Se refiere a qué si el tema tratado en la noticia implica al coronavirus o no \\
Subtema & A qué tipo de acontecimiento se refiere la publicación \\
Información & La noticia publicada \\
Actividad & En dónde o cómo se generó la información, en esto los ítems son: \\
& 1. Información oficial/ boletín \\
& 2. Hecho \\
& 3. Entrevista \\
4. Testimonio & 6. Protesta \\
Fuente & Quién es la fuente de la información \\
Cargo & El cargo que ocupa la fuente de la información \\
Tipo de cargo & Qué tipo de cargo tiene la fuente de información \\
\hline
\end{tabular}




\section{Resultados}

En el estudio se capturaron mil 319 noticias publicadas en los medios de comunicación analizados: El Sur y Novedades de Acapulco, de prensa; Televisa Acapulco y Sur Tv, de televisión; Informe 24 y Nuestras Noticias, de radio.

La mayor parte del porcentaje de la información analizada corresponde a los medios escritos, debido a que el espacio destinado para la publicación es mayor al tiempo que tienen los medios electrónicos (radio y televisión) para difundir noticias, porque parte de la emisión se dedica también a llamadas telefónicas o entrevistas en directo, lo que reduce la cantidad de notas informativas que se transmiten. De tal manera que noticias de periódicos hay $65 \%$, de radio $18 \%$ y televisión 17.1\%. (Gráfica 1).

\section{Gráfica 1}

Tipo de medio en que se monitorearon las noticias publicadas

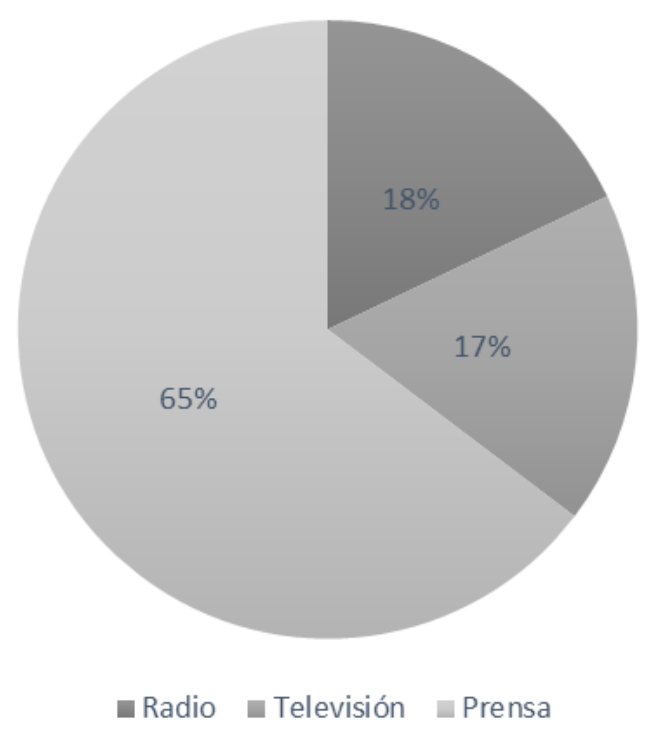

\section{Gráfica 2}

Temas que se trataron en los días monitoreados

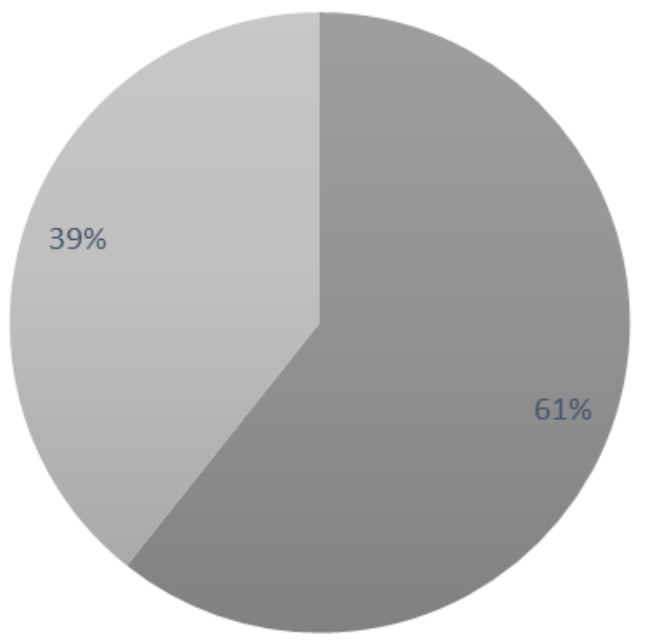

a COVID- $19 \backsim$ No COVID- 19

Como se observa en la Gráfica 2, de las mil 319 noticias que se publicaron durante las fechas de análisis la mayor parte $(60.7 \%)$ de la información tiene que ver con la COVID- 19, mientras que las noticias no relacionadas con el tema fueron del $39.3 \%$.

Lo anterior significa que la mayor parte de las noticias publicadas fueron con respecto a la pandemia y dedicadas a varios asuntos y con diversos actores, declaraciones oficiales, acciones gubernamentales, actividades de protesta, de solidaridad y desacatos a las disposiciones oficiales, cuyos porcentajes se mencionan en la Gráfica 3 y que se refieren a los principales asuntos ligados al tema. El alto porcentaje de noticias sobre la COVID- 19 se debe a que, como noticia en desarrollo y de secuencia, alrededor de ella se fueron produciendo acontecimientos nuevos o derivaciones (Alsina, 2005) y son a los que se refieren los subtemas encontrados en el monitoreo. 


\section{Gráfica 3}

Subtemas que se trataron relacionados al tema de la COVID- 19

\begin{tabular}{|r|c|}
\hline Medidas & $17.8 \%$ \\
\hline Evolución & $12.3 \%$ \\
\hline Cierres/ Suspensiones & $9.9 \%$ \\
\hline Reapertura & $6.8 \%$ \\
\hline Apoyos & $6.1 \%$ \\
\hline Desacatos & $4.9 \%$ \\
\hline Turismo & $3.4 \%$ \\
\hline Bloqueos & $3.3 \%$ \\
\hline Reclaman apoyos & $3.1 \%$ \\
\hline Dispersión & $3.0 \%$ \\
\hline Atención hospitalaria & $2.5 \%$ \\
\hline Otras & $26.9 \%$ \\
\hline
\end{tabular}

En el registro se identificaron 68 subtemas, de estos los de mayor frecuencia fueron las informaciones que tenían que ver con las medidas sanitarias (17.8\%), es decir, aquellas acciones en las que se hacían recomendaciones para evitar los contagios; tanto para las personas como para prestadores de servicios; así como la instalación de módulos sanitarios, tanto para la desinfección como para la realización de pruebas de detección del virus. Estas noticias corresponden a la categoría de desarrollo, porque produjeron acontecimientos nuevos en tanto la información se iba actualizando conforme pasaban los días.

A la misma cualidad responde la información de los gobiernos federal como estatal, el subtema de la evolución de los contagios, con una cobertura colocada en el segundo lugar con $12.3 \%$. Esta información corresponde al reporte diario que emitían en las conferencias de prensa, tanto en la matutina del presidente Andrés Manuel López
Obrador, como en la del subsecretario de Salud, Hugo López Gatell; también en las conferencias transmitidas en la página de Facebook del gobierno estatal, encabezada por el gobernador de Guerrero, Héctor Astudillo Flores y el titular de la Secretaría de Salud, Carlos de la Peña Pintos. Los datos proporcionados en estas transmisiones eran retomados por los medios como parte de su cobertura informativa cotidiana.

El tipo de noticias de secuencia son los subtemas de cierres (9.9\%), los cuales describen a las actividades que se han suspendido, así como los efectos que han causado y las declaraciones de diferentes actores sociales con respecto a esa medida.

El subtema de reapertura (6.8\%) tiene que ver con la economía, porque da cuenta de las exigencias para permitir el funcionamiento de los diferentes negocios hoteleros, restauranteros, centros comerciales, entre otros y que principalmente era peticiones de los empresarios de esos ramos, pero 
también por los empleados que estaban viendo mermados sus ingresos o siendo despedidos.

El subtema de apoyos (6.1\%) refiere las noticias de acciones que los gobiernos ya sea estatal o municipal hicieron en favor de la población, principalmente a través de la distribución de despensas principalmente, Su difusión resultó alta porque se trata de información oficial que formó parte de los convenios publicitarios que tienen los gobiernos con los medios de comunicación.

Con respecto a los desacatos $(4.9 \%)$, estas incluyen noticias que se recolectaron a través de recorridos de los reporteros en las que se presentó que la población que no cumple con las indicaciones gubernamentales para contener los contagios, tales como no usar cubrebocas ni guardar una sana distancia,en filas para obtener algún tipo de servicio o consumir bienes.

En el subtema del turismo (3.4\%) se codificaron las notas informativas que señalan la baja ocupación hotelera y afluencia de visitantes en Acapulco, principalmente, pero también en otros polos turísticos como Ixtapa- Zihuatanejo y Taxco.

Con respecto a los bloqueos (3.3\%) se trató de la cobertura relacionada con cierres de calles o carreteras que hicieron vecinos o gremios ya sea en demanda de apoyos para subsanar sus necesidades económicas, como en reclamo de que se les permitiera trabajar. Lo mismo que los reclamos de apoyos (3.1\%), aunque estos no necesariamente recurrieron a los bloqueos de calles o avenidas.

En el asunto de las dispersiones (3.0\%) fueron acciones, que se dieron a conocer gracias a la información oficial, realizadas por el gobierno municipal con la coordinación de la Secretaría de Marina para suspender aglomeraciones de personas -en fiestas, eventos deportivos o de otros tipos- que era denunciados y a los cuales acudían las autoridades para cancelarlos.

Con respecto a la ocupación hospitalaria $(2.5 \%)$, esta indicaba las quejas de quienes pretendieron ingresar a sus familiares a los nosocomios, pero que no pudieron porque estaban saturados; en esta parte también se hacían recorridos de periodistas en los sitios recogiendo testimonios.

Como se señaló líneas arriba fueron 68 subtemas identificados relacionados con las noticias sobre el coronavirus difundidas en los medios de comunicación analizados, de tal manera que el resto 57 corresponden a los que tienen menos de 20 menciones.

\section{Gráfica 4}

Actividad en la que se originó la información publicada

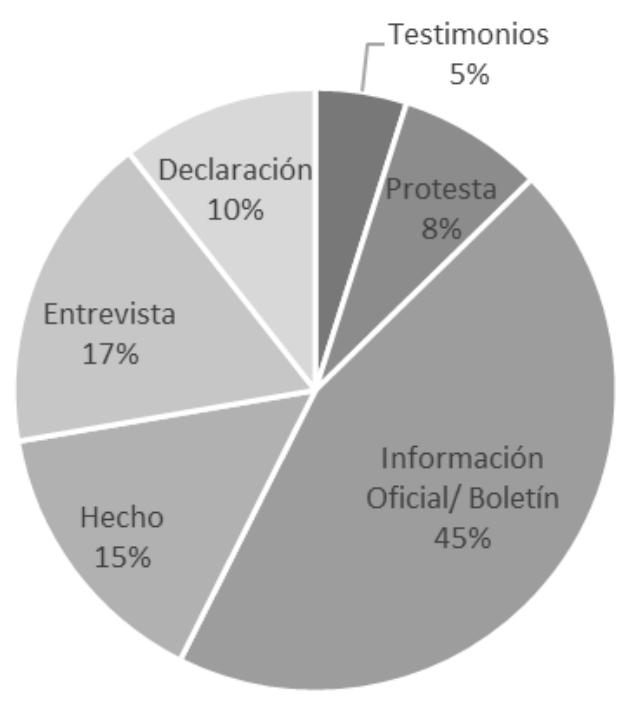


En tanto que el $17 \%$ de las noticias fueron producto de entrevistas hacia los diferentes actores; asimismo el $15 \%$ de las noticias publicadas tuvo como origen algunos hechos o eventos programados para ser cubiertos por los periodistas. Por otro lado, $10 \%$ fue información originada en declaraciones y el $8 \%$ en el contexto de las protestas que se realizaron en diferente momento.

\section{Gráfica 5}

Fuente de la información publicada y relacionada con la COVID- 19

\begin{tabular}{|r|c|}
\hline Héctor Astudillo Flores & $47.7 \%$ \\
\hline Adela Román Ocampo & $28.0 \%$ \\
\hline Ayuntamiento de Acapulco & $20.1 \%$ \\
\hline Periodistas & $19.6 \%$ \\
\hline Carlos de la Peña Pintos & $15.0 \%$ \\
\hline Salud estatal & $11.7 \%$ \\
\hline Ernecinos & $9.8 \%$ \\
\hline Transportistas & $8.4 \%$ \\
\hline
\end{tabular}

Las fuentes que aparecieron con más frecuencia en la información publicada son el gobernador del estado Héctor Astudillo Flores (47.7\%) y, la presidenta municipal de Acapulco, Adela Román Ocampo (28\%), mientras que las diferentes direcciones del Ayuntamiento de Acapulco originaron el $20.1 \%$ de las notas (Gráfica 5).

Los periodistas con informaciones sobre sus pesquisas fueron fuente en el $19.6 \%$ de las noticias; en tanto que el secretario de Salud del gobierno estatal, Carlos de la Peña Pintos, aparece como fuente de información en el 15\%; mientras que Salud estatal en un $11.7 \%$. Por su parte, vecinos que se movilizaron por alguna causa aparecieron en un 9.8\% de las piezas analizadas, y Salud federal en un 8.4\%. El secretario del Ayuntamiento de Acapulco, Ernesto Manzano Rodríguez, es considerado en el $7.9 \%$ de la información recolectada como fuente de las noticias, así como los transportistas en la misma proporción. 


\section{Gráfica 6.}

Tipo de cargo que ostentó la fuente de información

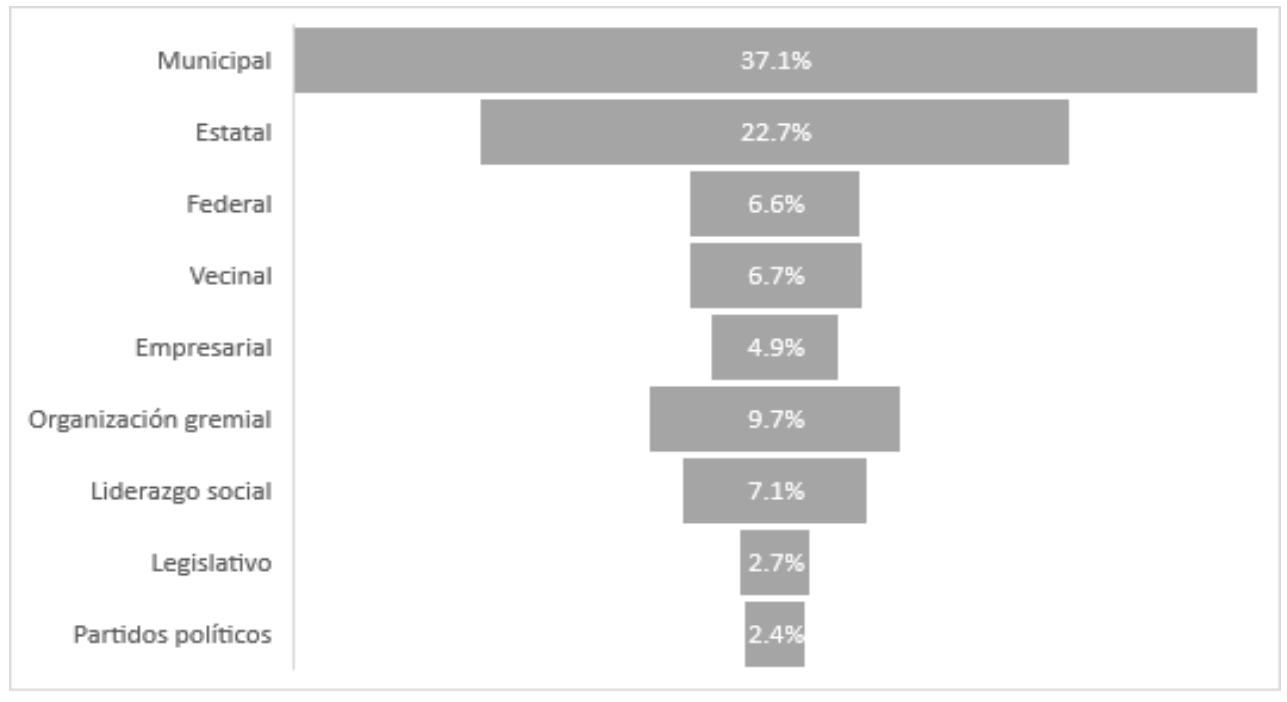

En el tipo de cargo de la fuente (Gráfico 6) prevaleció las municipales por el número de personal y dependencias que actúan, por ello aparece en un $37.1 \%$, mientras que los de carácter estatal, la frecuencia de aparición es de $22.7 \%$, las organizaciones gremiales con $9.7 \%$, y los de liderazgo social con $7.1 \%$. En el caso de las dependencias federales aparece un $6.6 \%$ y las vecinales con $6.7 \%$.

\section{Conclusiones}

Como objetivos de esta investigación se plantearon conocer cuál es la cobertura periodística en torno al coronavirus en medios con sede en Acapulco, el análisis de la información que se publicó en torno al tema, así como conocer las fuentes y actores, actividades y acciones en que se originó la información respectiva.

Los resultados de este análisis y monitoreo de la cobertura noticiosa de la COVID- 19 indican que la mayor parte de la información que publicaron los medios registrados, el $61 \%$ fue en torno al coronavirus y el 39\% sobre otros temas. Esta conclusión se explica por las medidas de las afectaciones que causó el virus SARS- CoV- 2, así como por el número de contagios y decesos que ocasionó.

Las medidas y recomendaciones sanitarias para tratar de contener las infecciones causaron controversias y conflictos, por el cierre de los espacios de recreación, comerciales, escolares y de todo tipo - fuera de las actividades esenciales permitidas-, ya que esto repercutió económicamente en un amplio sector de la población. Estas secuelas generaron un amplio abanico de subtemas o asuntos que fueron cubiertos 
por los medios, y que estaban ligadas al tema del coronavirus.

El porcentaje de los subtemas como las medidas de restricción (17.8\%), la evolución de la enfermedad (12.3\%), los cierres y suspensiones de actividades $(9.9 \%)$ son los tres más frecuentes que indican la preponderancia de las fuentes oficiales de los gobiernos, de los tres niveles, para transmitir la información; y que como se ha señalado arriba, se debe a la garantía de la publicación de los boletines e información de los eventos organizados, ya sea en actos públicos o conferencias de prensa, gracias a los convenios publicitarios que se tienen con los medios de comunicación.

Esto se reitera en la Gráfica 4, en donde la información oficial o boletines de prensa tiene $45 \%$ de frecuencia, las entrevistas a los actores un $17 \%$, mientras que los hechos están en un $15 \%$ de repetición.

Lo mismo ocurre con las fuentes informativas, en donde el gobernador Héctor Astudillo Flores tiene $47.7 \%$ de frecuencia en el monitoreo; la presidenta municipal de Acapulco, Adela Román Ocampo, un 28\% de periodicidad en las noticias analizadas; lo mismo ocurre con el Ayuntamiento de Acapulco, a través de sus diferentes direcciones, que aparece con $20.1 \%$ y los periodistas en sus recorridos de verificación del contexto tiene $19.6 \%$.

En términos generales, la información noticiosa que prevaleció en los medios de comunicación analizados es que la comunicación oficial y actores institucionales tuvieron una mayor cobertura por el número de notas informativas que se difundieron en que las autoridades estatal y municipal de Acapulco el gobernador Héctor Astudillo Flores y la alcaldesa Adela Román Ocampo- fueron los actores políticos que sobresalieron en el periodo analizado.

En el caso de la información publicada por los medios no se encontraron noticias falsas ni teorías conspirativas, predominó la información oficial en torno a la enfermedad; espacio para las voces afectadas para la pandemia, ya sea en entrevistas, declaraciones y testimonios; pero también en los hechos de las protestas que realizaron grupos gremiales dedicados a algunas de las actividades afectadas por la falta de ingresos y que exigían ayuda para sobrevivir.

Tanto las noticias en desarrollo como en las de secuencia, según la tipología de Alsina (2005) dieron cuenta de los diferentes factores que se generaron en torno al tema de la pandemia, y los comportamientos públicos, declaraciones de actores, decesos y contagios.

Por otro lado, la teoría de la agenda setting McCombs (2006), que señala que la información que aparece en los medios de comunicación masiva influye en nuestra percepción de los asuntos importantes, pero también este enfoque busca responder al efecto que causa en las personas la información que se publica; sin embargo, este trabajo adolece de ese complemento, por las limitaciones de recursos humanos, materiales y financieros.

Esta ausencia no demerita la importancia del trabajo, porque así como la UNESCO (2020) ha citado sus estimados de volumen de información falsa, también es pertinente conocer en un estudio de 
caso como este que documente la cantidad, las fuentes y los acontecimientos que se convirtieron en noticia en torno a la COVID- 19 en un periodo de tiempo, como el que aquí se ha establecido.

Ciertamente un elemento de relevancia es la exposición a esa información, el hecho de que esta información se encuentre disponible al público a través de los medios de comunicación masiva y pueda ejercer influencia, como indica el modelo teórico de la agenda setting.

Si bien esta información difundida a través de los medios analizados en Acapulco estaba disponible, también lo estaban la información en las redes sociales virtuales a través de la Internet, en donde se pueden encontrar las mismas notas verificadas difundidas a través de los medios, que noticias falsas.
Pero los comportamientos no dependen solamente de la información vertida, sino también de las condiciones de las personas para cumplir con las recomendaciones sanitarias. Porque particularmente en Acapulco, la subsistencia depende de actividades económicas diarias lo cual los imposibilitó de mantenerse aislados en sus casas, porque hay trabajadores informales que tienen que salir a las calles y sus ingresos tiene que ver con la afluencia de las personas.

De cualquier forma, es importante $y$ pertinente desarrollar investigaciones sobre la influencia de la información en las redes sociales de internet y el efecto que tienen en las audiencias. Aún cuando todos los medios de comunicación masiva tengan espacios en las redes, no son las únicas fuentes de consulta.

\section{Referencias bibliográficas}

Alsina, M.R. (2005). La construcción de la noticia. Paidós.

Cantero de Julián, J. I., Sidorenko- Bautista, P., \& Herranz de la Casa, J.M (2020). Radiografía de la pandemia: Análisis de la cobertura periodística de la Covid- 19 en portadas de periódicos. Profesional de la Información, 29(5). https://doi.org/10.3145/epi.2020.sep.23

Casero- Ripollés, A. (2020). Impacto del Covid- 19 en el sistema de medios. Consecuencias comunicativas y democráticas del consumo de noticias durante el brote. El Profesional de la Información, 29(2). https://doi.org/10.3145/epi.2020.mar.23

Gunter, B. (2014). Los procedimientos de las investigaciones cuantitativas. In Bruhn Jensen, K (Edit). La comunicación y los medios. Metodologías de investigación cualitativa y cuantitativa (pp. 379- 424). FCE.

Hernández Ramírez, M.E. (1995) La producción noticiosa. UdeG.

Hernández Sampieri, R., Fernández Collado, C. \& Baptista Lucio, P. (2003). Metodología de la investigación. McGraw Hill.

Hjarvard, S. (2014). El estudio de la producción de noticias. In Bruhn Jensen, K (Edit). La comunicación y los medios. Metodologías de investigación cualitativa y cuantitativa (pp. 145-172). FCE. 
Lázaro- Rodríguez, P., \& Herrera- Viedma, E. (2020). Noticias sobre el Covid- 19 y 2019-nCoV en medios de comunicación de España. El papel de los medios digitales en tiempos de confinamiento. El profesional de la comunicación, 29(3). https://doi.org/10.3145/epi.2020.may.02

Lozano, J.C. (1994). Hacia una consideración de análisis de contenido en la investigación de los mensajes comunicacionales. In Cervantes Barba, C (Edit). Investigar la comunicación. Propuestas iberoamericanas (pp. 135-157). Universidad de Guadajalara.

McCombs, M. (2006). Estableciendo la agenda. El impacto de los medios en la opinión pública y en el conocimiento. Paidós.

Observatorio Veracruzano de Medios. (2020a, junio23). ¿Cuáles fueron los actores o declarantes que aparecieron en la prensa digital veracruzana durante la contingencia sanitaria COVID-19?. https://bit.ly/3zkYFsm

Observatorio Veracruzano de Medios. (2020b, junio 25). ¿Quiénes hablaron y sobre qué temas en la prensa digital de Veracruz durante la COVID-19?. https://bit.ly/2YYjPzQ

Observatorio Veracruzano de Medios. (2020, junio 30). ¿Cuáles fueron los rasgos del discurso empleado en las noticias emitidas sobre el COVID- 19 en los portales digitales veracruzanos? https://bit.ly/3tN4Cgx

Organización Mundial de la Salud. (2020, abril 27). COVID- 19. Cronología de la actuación de la OMS. https://bit.ly/39jhB01

Trejo Delarbre, R. (20015). Intolerancia en línea. Entenderla, exhibirla, debatirla. In Campos, M. et al. Mensajes de odio y discriminación en las redes sociales (pp. 37-48). Consejo Nacional para Prevenir la Discriminación.

UNESCO. (2020). Periodismo, libertad de prensa y COVID- 19. https://bit.ly/3EqIgpT

Global Media Journal México, 18(35), 55-70, julio - diciembre 2021. 